\title{
Vehicle handling improvements through Steer-by-Wire
}

\author{
Jan Sterthoff ${ }^{1}\left[\right.$ C $\cdot$ Roman Henze ${ }^{1} \cdot$ Ferit Küçükay ${ }^{1}$
}

Received: 28 October 2020 / Accepted: 12 March 2021 / Published online: 6 April 2021

(c) The Author(s) 2021

\begin{abstract}
This paper focuses on handling improvements enabled through Steer-by-Wire systems, which have increasingly become subject of $R \& D$, as they not only offer the potential for improving vehicle handling but also have many advantages in combination with automated driving. Handling improvements through a steering ratio depending on vehicle speed, as well as steering-wheel angle, are known from Active Front Steering systems. A new overall concept is proposed, that also takes into account lateral and longitudinal acceleration as well as steering rate, which are all available signals in a production car. The overall concept is designed in an optimization process to modify a range of established characteristic parameters known from open-loop maneuvers and the objective evaluation of vehicle handling. In this context, validated models for a vehicle and a Steer-by-Wire system are used to obtain reliable results in simulation. Possibilities for tuning the non-linear steering behavior as well as improvements in the dynamic behavior, especially in yaw damping and response time, are demonstrated.
\end{abstract}

Keywords Steering $\cdot$ Steer-by-Wire $\cdot$ Vehicle dynamics $\cdot$ Vehicle handling

\section{Introduction}

In connection with the further advancing vehicle automation, Steer-by-Wire (SbW) systems are increasingly in the focus of development, as they enable the steering-wheel to be held stationary during automated driving. At the same time, these systems also have considerable potential for improving vehicle handling, which is an important aspect of the chassis development process. The improvement in vehicle handling through $\mathrm{SbW}$ is the subject of this paper.

With Steer-by-Wire the road wheels are not mechanically linked to the steering-wheel. The steering ratio can therefore be modified in a variety of ways. A steering ratio depending on vehicle velocity is known from Active Front Steering systems, e.g. [1, 2]. With a velocity-dependent steering ratio, the agility of the vehicle can be increased at low and medium velocities, whereas at high velocities a smooth and more stable handling of the vehicle is achieved. This established functionality is used as a starting point for the proposed overall concept.

Jan Sterthoff

j.sterthoff@tu-braunschweig.de

1 Institute of Automotive Engineering, Technische Universität Braunschweig, Braunschweig, Germany
Additionally, the variable steering concept uses lateral acceleration as an input to improve the steering behavior. Another implementation of a steering ratio depending on lateral acceleration is described in $[3,4]$, to bring the self-steering gradient (eigenlenkgradient) closer to neutral steering during constant cornering. For the design of the proposed concept, other characteristic values than the self-steering gradient are optimized in this paper.

For the modification of vehicle behavior at dynamic steering inputs, the concept of lead steering has been proposed in research [5, 6], but has never been used in Active Front Steering due to a large overshoot in yaw rate and potential backlashes in steering-wheel torque. With Steer-byWire systems backlashes in steering-torque can be avoided because the road wheels and steering-wheel are not mechanically connected. Due to this advantage, an enhanced version of lead steering is developed and included in the proposed overall concept.

The variable steering ratio concept, which takes into account all of the inputs mentioned above, is designed in an optimization process to improve a broad range of characteristic parameters from the field of vehicle handling. The impact of the variable steering on vehicle handling is evaluated and discussed in several open-loop test maneuvers. 


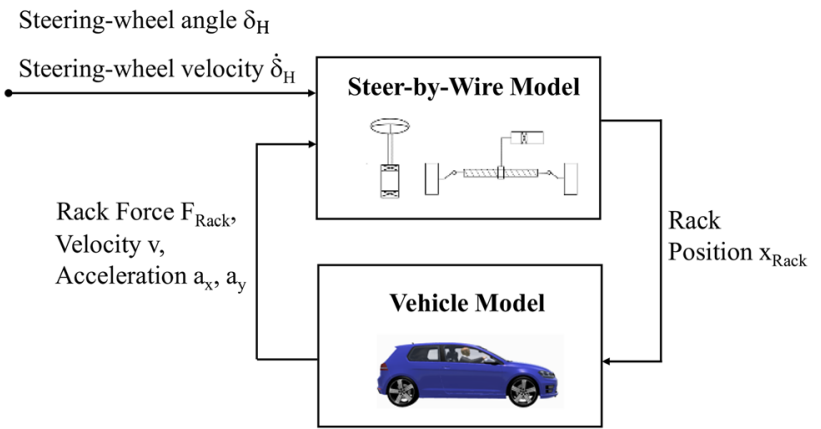

Fig. 1 Coupling of vehicle and SbW simulation models

\section{Vehicle and Steer-by-Wire model}

For the design of the variable steering ratio a Steer-by-Wire and a vehicle simulation model are coupled, Fig. 1. The variable steering ratio functionality described in the following section is placed inside the SbW model and is used for the calculation of the desired rack position.

All necessary inputs for the SbW model, except the maneuver specific steering-wheel angle and steering-wheel velocity, are calculated and supplied by the vehicle model, Fig. 1.

To achieve reliable simulation results, valid models, both for the vehicle and for the Steer-by-Wire system, are essential. For the vehicle model the commercial simulation environment of IPG CarMaker is used [7]. This simulation environment allows a detailed parameterization of the vehicle, especially of the elastokinematics of the chassis and the integration of a Pacejka tire model, which is of great importance for the analysis of the vehicle handling properties. The vehicle model is parametrized as a compact class car and is validated by measurements on a test site. The validation

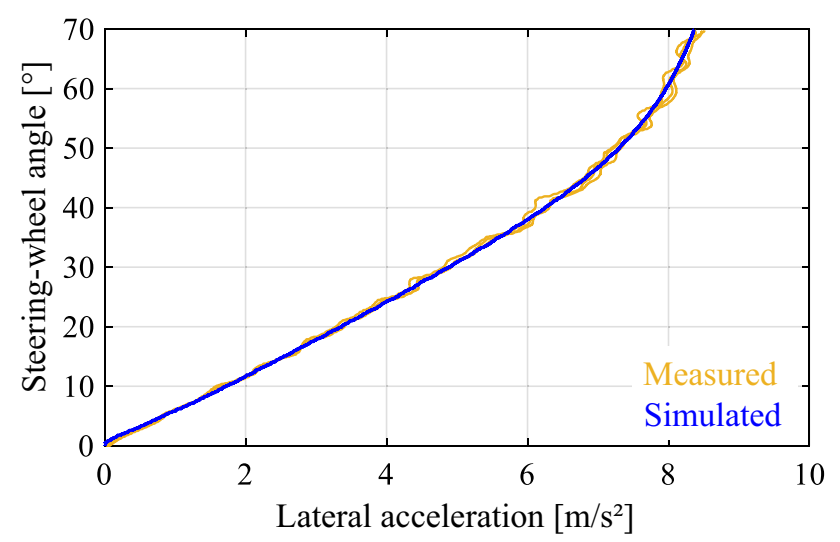

Fig. 2 Validation of vehicle model in a steering ramp maneuver at $\mathrm{v}=100 \mathrm{~km} / \mathrm{h}$

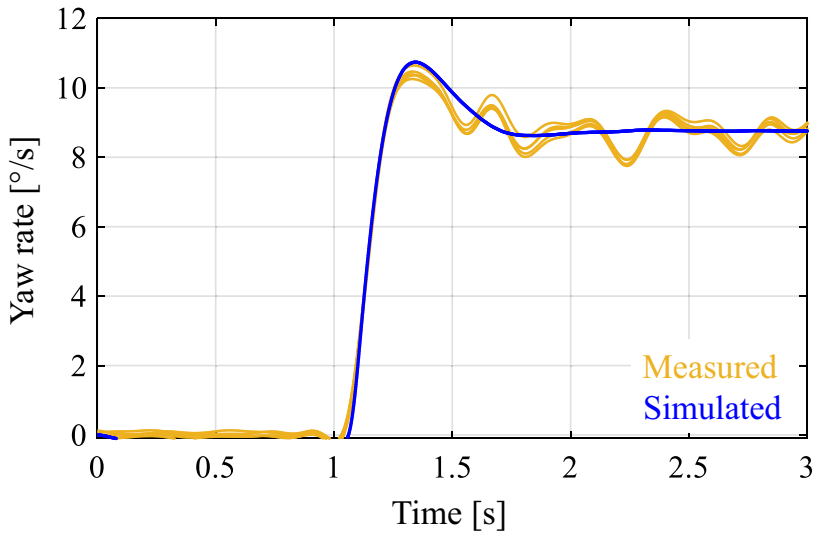

Fig. 3 Validation of vehicle model in a step-steering maneuver at $\mathrm{v}=100 \mathrm{~km} / \mathrm{h}$, oscillations in measured data due to cross grooves of the test site

measurements include the maneuver steering angle ramp at constant driving speed and the maneuver step-steering. Both maneuvers are performed with the help of a steering robot and repeated multiple times. The validation results are shown in Fig. 2 for the stationary steering ramp maneuver as well as in Fig. 3 for the dynamic step-steering. In both maneuvers, a high agreement up to the limit of driving dynamics is achieved.

The physical Steer-by-Wire model contains the following components to simulate the transfer behavior from steeringwheel angle $\delta_{\mathrm{H}}$ to rack position $\mathrm{x}_{\mathrm{Rack}}$, which is ultimately transmitted to the vehicle:

- First order differential equation for the steering motor with back electromotive force (EMF) according to [8, 9] and saturation of maximum power $(800 \mathrm{~W})$,

- Inertia and damping effects of the steering rack are reproduced by a single-mass oscillator according to [10], masses of the electric motor and screw drive are converted to the rack level,

- A detailed friction model for the steering gear called Exponential-Spring-Friction (ESF) according to [11],

- Time delays for communication (1-2 ms) of the controller.

The SbW model is validated on a Hardware-in-the-Loop (HiL) test rig, Fig. 4, through comparison with a real SbW system supplied by a manufacturer.

Within the scope of validation, the dynamic transfer behavior from steering-wheel angle to rack position in the frequency domain is particularly important. In this context, Fig. 5 shows the normalized amplitude of rack position $\mathrm{x}_{\text {Rack }}$ with respect to steering-wheel angle $\delta_{\mathrm{H}}$ as well as the corresponding phase angle in a steering sine sweep maneuver from $\mathrm{f}=0.2$ to $2.5 \mathrm{~Hz}$ at a constant driving velocity of 


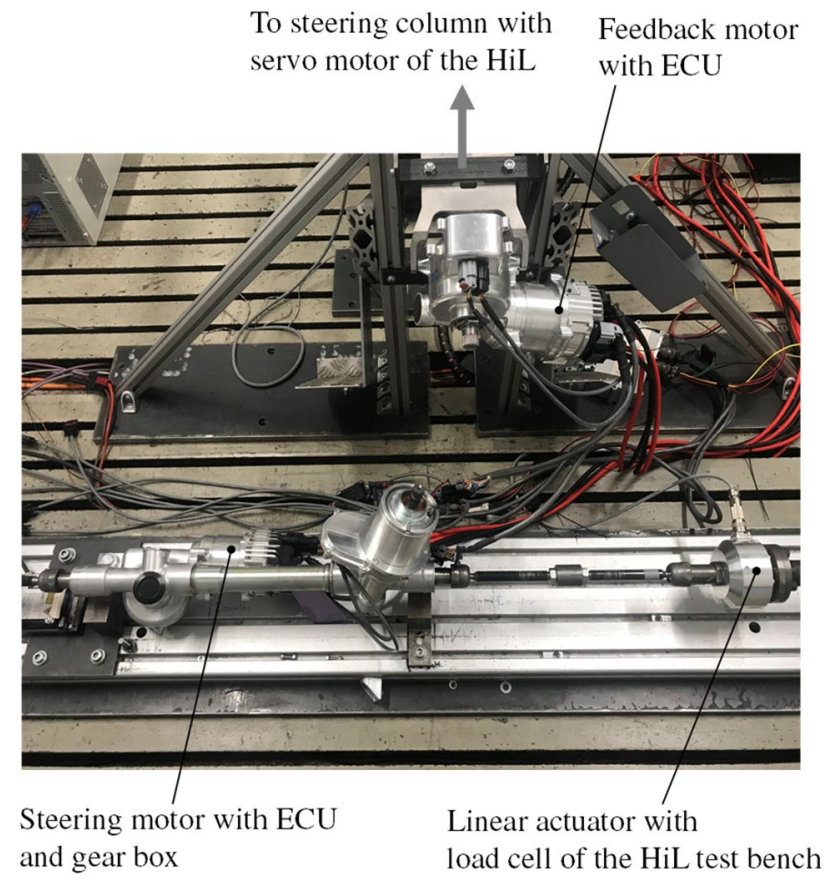

Fig. 4 Hardware-in-the-Loop test rig with Steer-by-Wire system
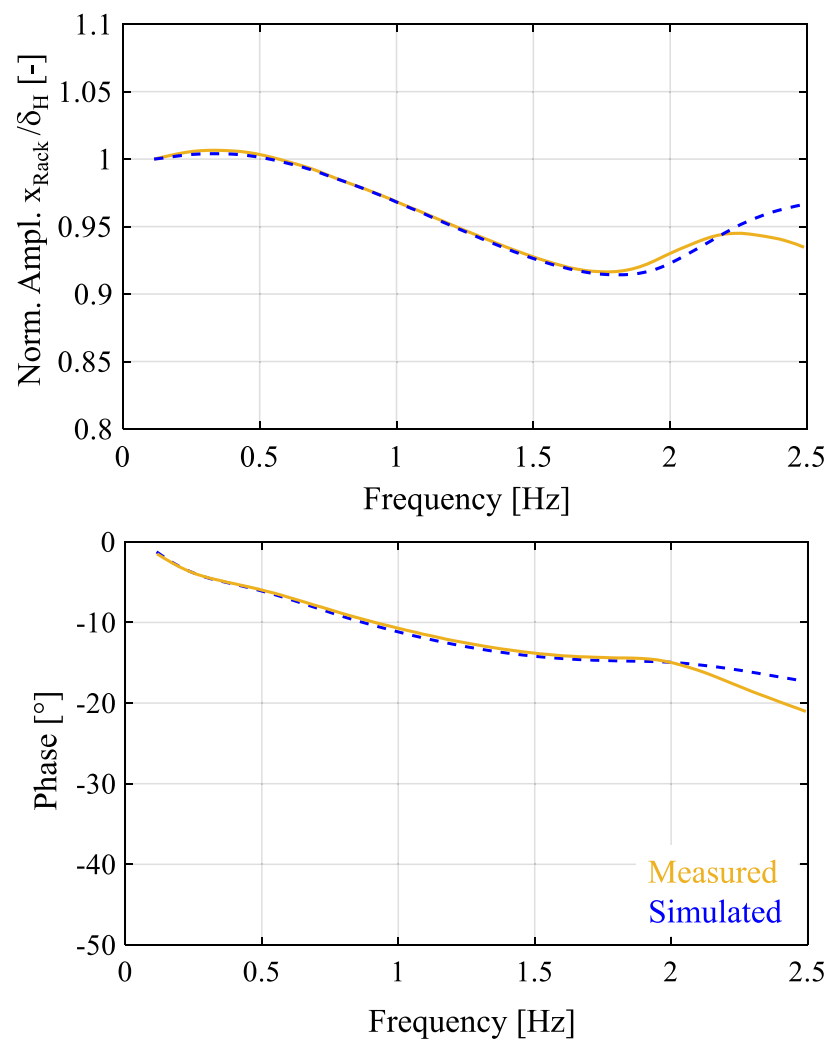

Fig. 5 Validation of SbW model in a steering sine sweep maneuver on the HiL test $\operatorname{rig}\left(\delta_{\mathrm{H}}=20^{\circ}, \mathrm{v}=100 \mathrm{~km} / \mathrm{h}\right)$ $\mathrm{v}=100 \mathrm{~km} / \mathrm{h}$, measured on the HiL test rig. A satisfying match of the model and the real system, especially up to $\mathrm{f}=2 \mathrm{~Hz}$, is reached. At $\mathrm{f}=2.5 \mathrm{~Hz}$, the maximum deviation between model and real SbW system is three percent in amplitude and the difference in time delay is about three milliseconds. In relation to the overall transfer behavior of the coupled system, consisting of SbW model and vehicle model, a deviation of this magnitude is of minor relevance.

\section{Layout of variable steering ratio}

The proposed overall layout of the variable steering ratio is shown in Fig. 6. It consists of two lookup tables and one second order filter. The impact of velocity on vehicle handling, also known from Active Front Steering systems, is achieved through lookup table LuT1.

The desired influence of lateral and longitudinal acceleration, as well as steering rate, on vehicle handling is realized through an additional rack position $\mathrm{x}_{\text {Rack,Add- }}$ This additional rack position consists of two components. The first component, based on lateral and longitudinal acceleration, is determined through lookup table LuT2. The steering rate, multiplied by a constant factor $T_{\mathrm{V}}$, is passed through a filter of second order to yield the second component of the additional rack position $\mathrm{x}_{\text {Rack,Add }}$. To take into account the fact that the dynamic vehicle transfer behavior changes with driving velocity [12], the constants $\mathrm{T}_{1}$ and $\mathrm{T}_{2}$ of the filter are made dependent on velocity, too.

The time constants $T_{1}$ to $T_{4}$ as well as the values of the two lookup tables LuT1 and LuT2 are determined by using a nonlinear least-squares solver (Levenberg-Marquardt algorithm). The solver iteratively adjusts the selected initial values for the time constants and look up tables until the difference between simulated vehicle behavior and a predefined target behavior, e.g. based on the characteristic parameters in Table 1, is minimized in terms of a cost function.

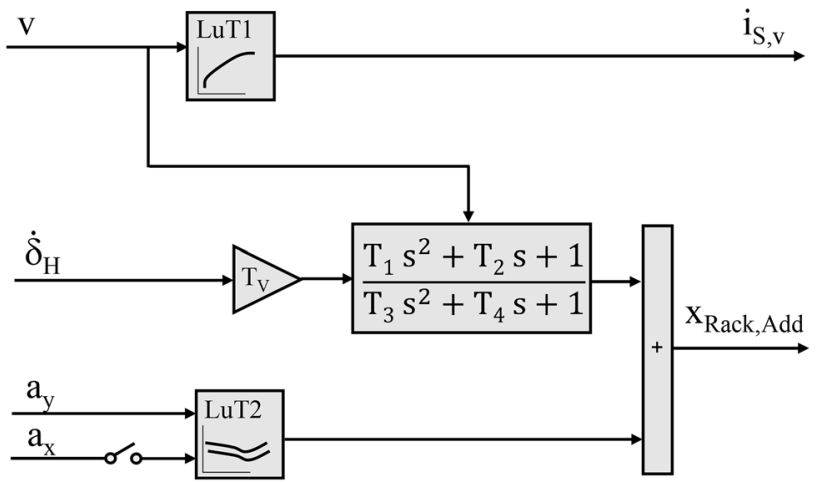

Fig. 6 Layout of the variable steering ratio concept 
Table 1 Characteristic parameters and values for the basic vehicle (compact class) as well as the target behavior

\begin{tabular}{lllll}
\hline & Char. Parameter & Basic Vehicle & Target & Test \\
\hline Agility & $\left(\dot{\psi} / \delta_{\mathrm{H}}\right)_{30 \mathrm{~km} / \mathrm{h}}$ & $0,22 \% \mathrm{~s}$ & $+50 \%$ & Steady state cornering at $\mathrm{a}_{\mathrm{y}}=4 \mathrm{~m} /$ \\
& $\left(\dot{\psi} / \delta_{\mathrm{H}}\right)_{80 \mathrm{~km} / \mathrm{h}}$ & $0,35 \%$ & $+20 \%$ & $\mathrm{~s}^{2}$ \\
& $\left(\dot{\psi} / \delta_{\mathrm{H}}\right)_{160 \mathrm{~km} / \mathrm{h}}$ & $0,32 \% \mathrm{~s}$ & $+10 \%$ & \\
\multirow{3}{*}{ Steering behavior } & $\mathrm{a}_{\mathrm{y} \text { endLin }}$ & $5,10 \mathrm{~m} / \mathrm{s}^{2}$ & $+30 \%$ & Steering ramp at $\mathrm{v}=100 \mathrm{~km} / \mathrm{h}$ \\
& $\left(\delta_{\mathrm{H}} / \mathrm{a}_{\mathrm{y}}\right)_{85 \% \max }$ & $13,50 \%\left(\mathrm{~m} / \mathrm{s}^{2}\right)$ & $+20 \%$ & \\
Dynamic behavior & $\mathrm{U}_{\left(\dot{\psi} / \delta_{\mathrm{H}}\right)}$ & $25,5 \%$ & $-50 \%$ & Steering sweep \\
& $\mathrm{f}_{\varphi=-45^{\circ}}$ & $1,15 \mathrm{~Hz}$ & $+125 \%$ & \\
\hline
\end{tabular}

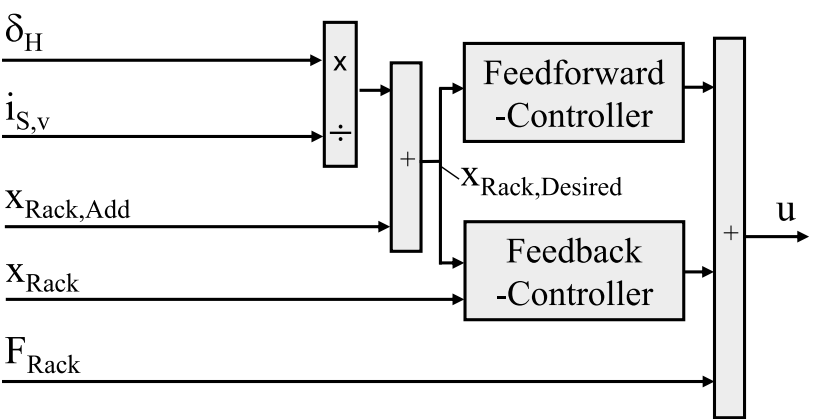

Fig. 7 Block diagram for control of rack position

In sum, lookup tables LuT1 and LuT2 are used to shape the stationary behavior of the vehicle, whereas $\mathrm{T}_{\mathrm{V}}$ in combination with the second order filter is used to design the dynamic behavior. The lookup tables contain a maximum of eight values per input to ensure applicability in a real vehicle on the test site.

Figure 7 shows how the velocity-dependent steering ratio $\mathrm{i}_{\mathrm{S}, \mathrm{v}}$ and the additional rack position $\mathrm{x}_{\text {Rack,Add }}$ are used to calculate the desired rack position $\mathrm{x}_{\text {Rack,Desired }}$. The actual rack position $\mathrm{x}_{\text {Rack }}$ is obtained directly from the rotor position angle of the steering motor at the rack. To meet the required accuracy and speed of the control task, a feedforward and a feedback controller are used in combination. The feedforward controller is used for compensation of inertia and friction at the rack of the steering system. Also, the rack force $F_{R a c k}$, as a result of simulated tire forces and aligning torque, is considered in the feedforward path. Instead of calculating the rack force from simulated tire forces, it can be estimated from the steering motor current in a real vehicle. The feedback controller is designed as a proportionalintegral-derivative controller (PID). The steering command $\mathrm{u}$, which is proportional to the steering motor voltage, is directly calculated from the three mentioned components.

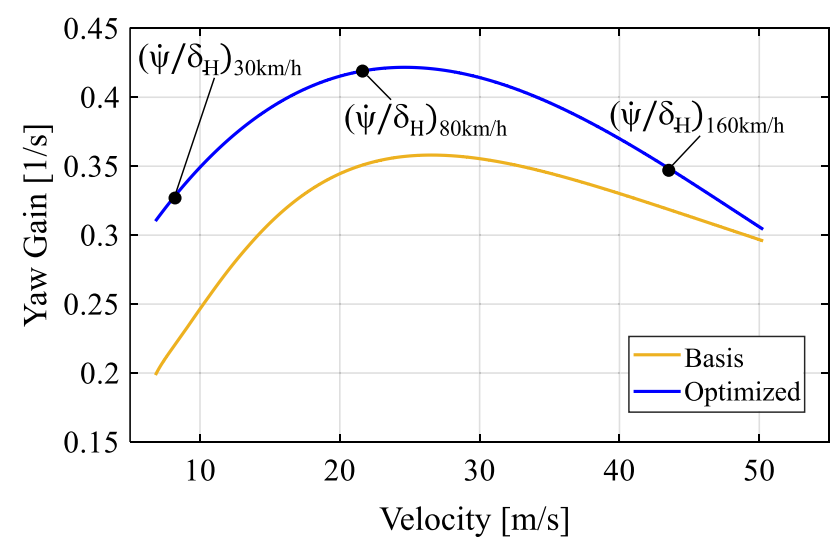

Fig. 8 Yaw gain over driving velocity at a constant lateral acceleration of $\mathrm{a}_{\mathrm{y}}=4 \mathrm{~m} / \mathrm{s}^{2}$

\section{Results}

The following optimized vehicle behavior is the result of an optimization process. In this process, the values of the lookup tables and the filter of the variable steering ratio, Fig. 6, are identified to achieve the desired target behavior. The desired target behavior is defined relative to a basic vehicle. The handling characteristics of the chosen basic vehicle correspond to those in Figs. 2 and 3 and can also be described through characteristic parameters. Table 1 shows the values of the selected characteristic parameters for the basic vehicle as well as the target behavior. The characteristic parameters are also marked in the following figures.

In the following, vehicle handling is divided into three aspects: agility, steering behavior, and dynamic behavior.

\subsection{Agility}

The agility of the vehicle is commonly evaluated by the yaw gain as a function of the driving speed $\psi / \delta_{\mathrm{H}}(\mathrm{v})$. Figure 8 shows the behavior of the basic vehicle as well as the optimized behavior in a constant lateral acceleration maneuver $\left(\mathrm{a}_{\mathrm{y}}=\right.$ const. $\left.=4 \mathrm{~m} / \mathrm{s}^{2}\right)$. During this maneuver, the velocity is increased steadily and the steering angle is adjusted to maintain a constant lateral acceleration. With this procedure, 


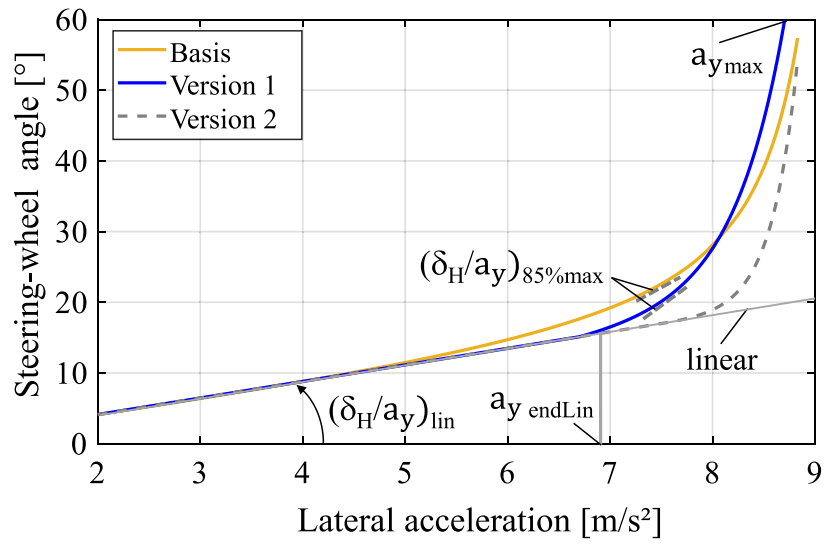

Fig. 9 Steering-wheel angle over lateral acceleration in a steering ramp maneuver at $\mathrm{v}=100 \mathrm{~km} / \mathrm{h}$ with characteristic parameters

the values for the lookup table LuT1 can be determined as a function of velocity without being influenced by lateral acceleration.

The target values for the yaw gain $\dot{\psi} / \delta_{\mathrm{H}}(\mathrm{v})$ in Table 1 were chosen with reference to [10] and [13]. The optimized vehicle shows much more agile handling at low and midspeed, characterized through a higher yaw gain $\dot{\psi} / \delta_{\mathrm{H}}$ at $\mathrm{v}=30$ and $80 \mathrm{~km} / \mathrm{h}$ according to Table 1 . To increase stability, the increased yaw gain $\dot{\psi} / \delta_{\mathrm{H}}$ is reduced at high speed, e.g. $v=160 \mathrm{~km} / \mathrm{h}$.

\subsection{Steering behavior}

The steering behavior is generally assessed using the steering-wheel angle over the lateral acceleration diagram. In this context, Fig. 9 shows the steering angle $\delta_{\mathrm{H}}$ over lateral acceleration $\mathrm{a}_{\mathrm{y}}$ for the basic vehicle (with modified yaw gain) as well as two further optimized versions in a steering ramp maneuver at $\mathrm{v}=100 \mathrm{~km} / \mathrm{h}$. With this type of maneuver execution, lateral acceleration can be increased independently of velocity in order to determine the values of lookup table LuT2. The overall behavior can be characterized through three characteristic parameters known from the objective evaluation of vehicle handling:

- the linear steering angle gradient: $\left(\delta_{\mathrm{H}} / \mathrm{a}_{\mathrm{y}}\right)_{\operatorname{lin}}$

- the length of the linear range: $\mathrm{a}_{\mathrm{y} \text { endLin }}$

- the gradient of steering-wheel angle when approaching the dynamic limit: $\left(\delta_{\mathrm{H}} / \mathrm{a}_{\mathrm{y}}\right)_{85 \% \max }$

When incorporating lookup table LuT2 to optimize steering behavior based on lateral acceleration, the previously specified yaw gain (Sect. 4.1 Agility) has to be taken into account. Within the linear range, the steering angle $\delta_{\mathrm{H}}$ is.

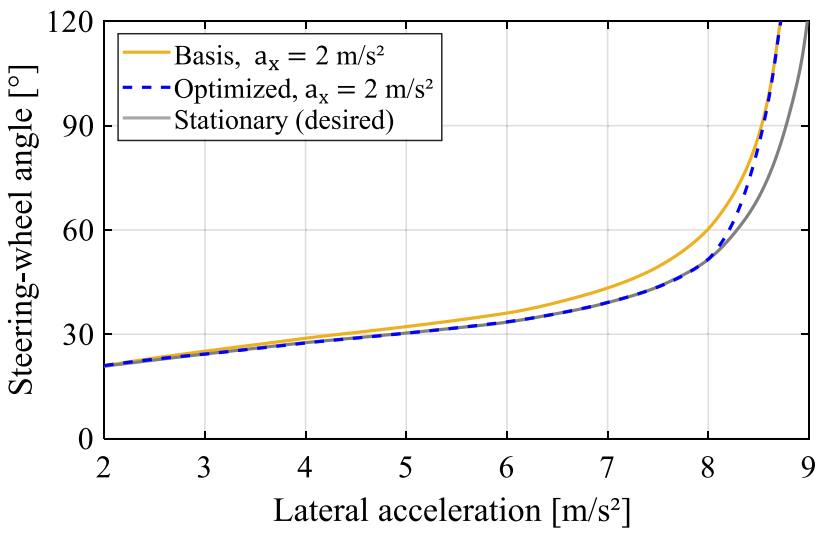

Fig. 10 Compensation of understeer due to the longitudinal acceleration of $\mathrm{a}_{\mathrm{x}}=2 \mathrm{~m} / \mathrm{s}^{2}$ while cornering

$\delta_{\mathrm{H}}=\left(\delta_{\mathrm{H}} / \mathrm{a}_{\mathrm{y}}\right)_{\operatorname{lin}} \cdot \mathrm{a}_{\mathrm{y}}$.

With the steady-state relationship between lateral acceleration $\mathrm{a}_{\mathrm{y}}$ and yaw rate $\dot{\psi}$

$\mathrm{a}_{\mathrm{y}}=\mathrm{v} \cdot \dot{\psi}$,

the linear steering angle gradient can be written as:

$\left(\delta_{\mathrm{H}} / \mathrm{a}_{\mathrm{y}}\right)_{\operatorname{lin}}=\frac{1}{\mathrm{v} \cdot \frac{\dot{\psi}}{\delta_{\mathrm{H}}}}$,

with $\dot{\psi} / \delta_{\mathrm{H}}$ denoting the yaw gain according to Fig. 8. Hence, the steering behavior in the linear range cannot be modified further, for example in the direction of neutral steering, without affecting the optimized yaw gain $\dot{\psi} / \delta_{\mathrm{H}}$. However, the length of the linear range $a_{y}$ endLin as well as the gradient $\left(\delta_{\mathrm{H}} / \mathrm{a}_{\mathrm{y}}\right)_{85 \% \max }$ can be modified as desired. A long linear range $\mathrm{a}_{\mathrm{y} \text { endLin }}$ and an appropriate notification of the dynamic limit, expressed through objective parameter $\left(\delta_{\mathrm{H}} / \mathrm{a}_{\mathrm{y}}\right)_{85 \% \max }$, are both important for good vehicle handling [14]. Version 2 in Fig. 9 proves, that it is possible to achieve a very long linear range, but it also features a very steep approach towards the dynamic limit, which is in general not desired. Version 1 , on the other hand, meets the target values from Table 1 and is, therefore, the preferred concept, with a significantly longer linear range than the basic vehicle and a slightly increased gradient $\left(\delta_{\mathrm{H}} / \mathrm{a}_{\mathrm{y}}\right)_{85 \% \max }$ to inform the driver about the dynamic limit early enough. Apart from the two shown versions, many different variations for the non-linear range are possible.

The proposed approach makes it possible to design the vehicle handling in an intuitive way. In the first step, the agility of the vehicle can be specified in terms of yaw gain with regard to velocity, and in the second step the steering behavior, especially in the non-linear range, can be tuned. 

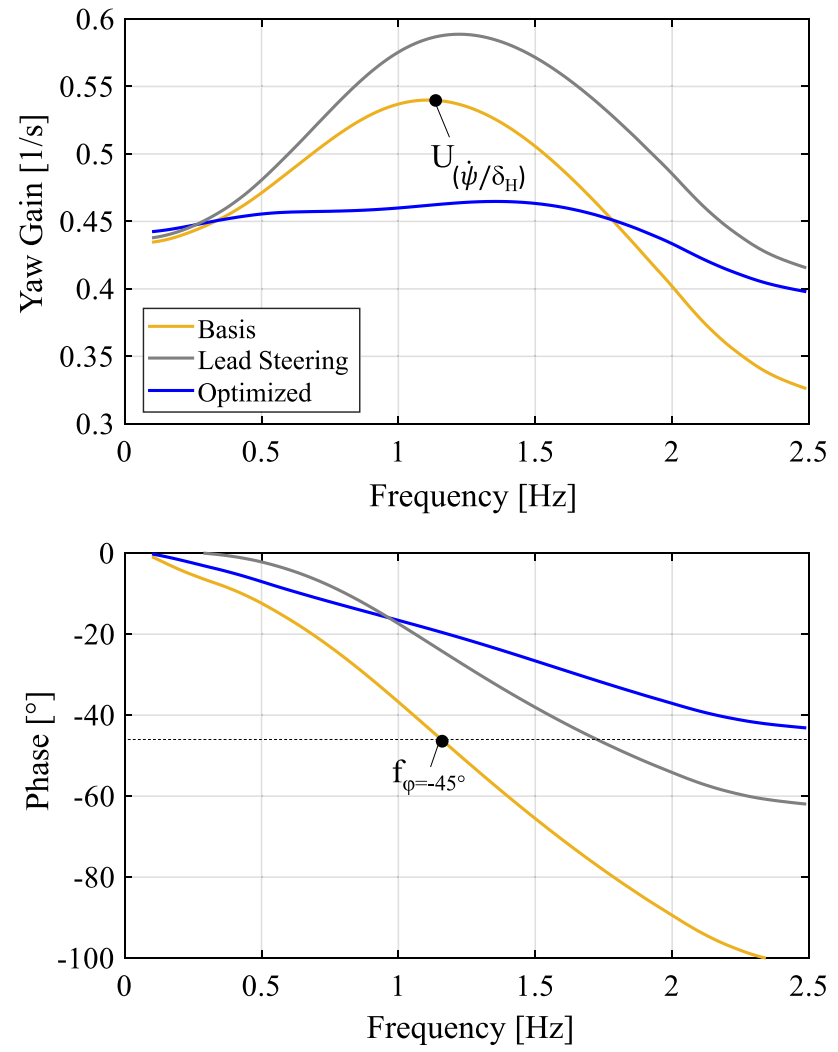

Fig. 11 Frequency response (amplitude and phase) in a steering sweep maneuver at $\mathrm{v}=100 \mathrm{~km} / \mathrm{h}$

If a longitudinal acceleration $\mathrm{a}_{\mathrm{x}}$ is applied during cornering, vehicles with front-wheel drive in particular show a tendency towards increased understeer. The reason for this effect is the reduced lateral force potential due to the wheel load transfer to the rear axle and the increased slip development at the driven front axle. By adding longitudinal acceleration as another dimension to lookup table LuT2, this increased understeer can partially be compensated for. Figure 10 shows the steering-wheel angle over lateral acceleration in a steady state cornering maneuver on a constant radius $(\mathrm{r}=100 \mathrm{~m})$ with and without significant longitudinal acceleration. The basic vehicle, without understeer compensation, shows increased understeering when an additional longitudinal acceleration of $\mathrm{a}_{\mathrm{x}}=2 \mathrm{~m} / \mathrm{s}^{2}$ is applied. The optimized vehicle, with longitudinal acceleration as a second input to lookup table LuT2, can achieve the same steering behavior as in stationary conditions until $85 \%$ of the maximum lateral acceleration, which in general is beneficial. Above $85 \%$ of the maximum lateral acceleration, the stationary behavior cannot be maintained, because the lateral force potential at the front axle is almost completely utilized.
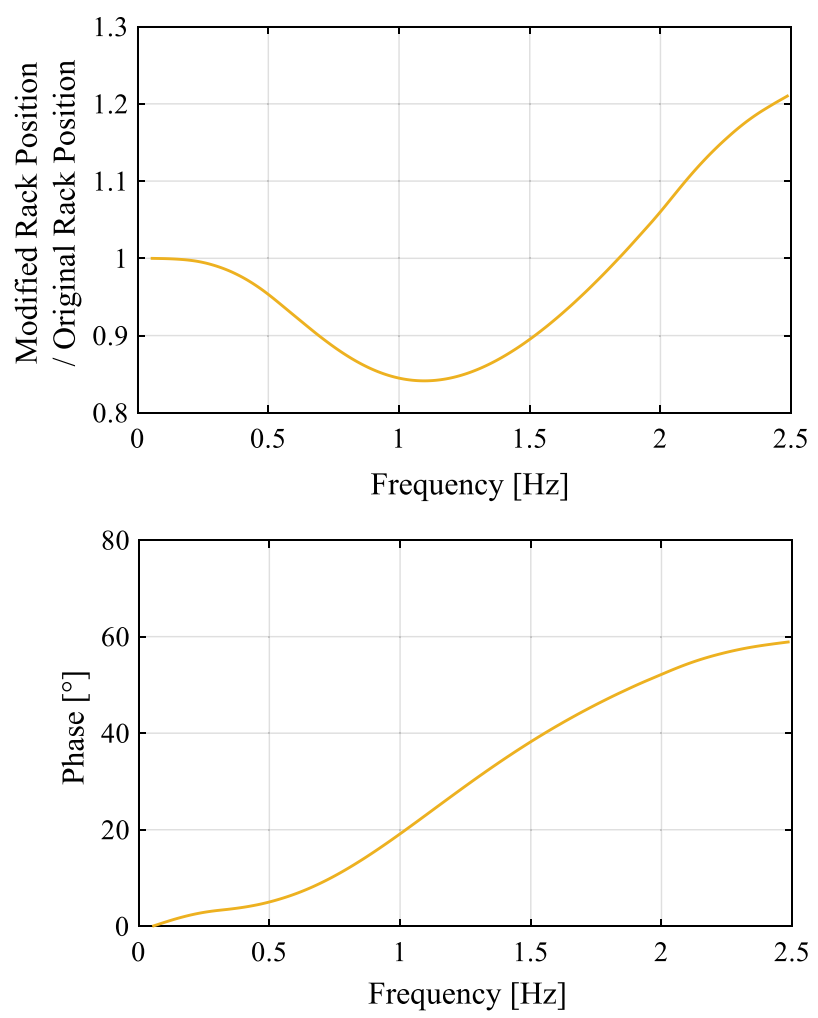

Fig. 12 Modified rack position, including $\mathrm{x}_{\text {Rack,Add, }}$ with respect to the original rack position as well as the corresponding phase angle in the frequency domain

\subsection{Dynamic behavior}

To modify the dynamic behavior of the basic vehicle, a steering sine sweep at a driving speed of $\mathrm{v}=100 \mathrm{~km} / \mathrm{h}$, covering a frequency range from $\mathrm{f}=0.2$ to $2.5 \mathrm{~Hz}$, is examined. In this maneuver, the vehicle response in the frequency domain, especially the yaw response with respect to the steering-wheel input, is of importance, Fig. 11. Passenger vehicles have a yaw natural frequency, at which the yaw reaction is often significantly greater compared to stationary conditions. The increased yaw reaction at the yaw natural frequency is described by the objective parameter $\mathrm{U}_{(\dot{\psi} / \delta \mathrm{H})}$, which should be small for good vehicle handling $[15,16]$. Towards higher frequencies $(\mathrm{f}>2 \mathrm{~Hz}$ ) the yaw response drops below the stationary value due to the inertia of the vehicle acting as a low-pass filter. The absolute value of the phase angle of the yaw response becomes larger with higher frequencies, resulting in a significant time delay between steering input and vehicle reaction. To decrease this time delay and make the vehicle response faster, lead steering has been proposed in [5,6]. With lead steering, the road wheel angle $\delta$ is increased proportionally to the steering-wheel rate $\dot{\delta}_{\mathrm{H}}$ : 
$\delta=\frac{1}{i_{\mathrm{s}}}\left(\delta_{\mathrm{H}}+\mathrm{T}_{\mathrm{V}} \cdot \dot{\delta}_{\mathrm{H}}\right)$

with $\mathrm{i}_{\mathrm{s}}$ denoting the overall steering ratio. The time constant $\mathrm{T}_{\mathrm{V}}$ determines the amount of additional road wheel angle [6].

The frequency, $f_{\varphi=-45^{\circ}}$, at which the phase angle reaches a value of $\varphi=-45^{\circ}$, can be used as an objective parameter for quantification of the response speed. In general, the response speed should be as fast as possible $[15,17,18]$. With lead steering, the frequency $\mathrm{f}_{\varphi=-45^{\circ}}$ can be increased significantly. However, the value $\mathrm{U}_{(\dot{\psi} / \delta \mathrm{H})}$ is also increased, leading to an undamped and undesired behavior near the yaw natural frequency, Fig. 11.

The proposed solution according to Fig. 6 combines lead steering with a filter of second order. Lead steering in combination with the specifically designed filter can achieve both, an increase of $\mathrm{f}_{\varphi=-45^{\circ}}$ and a decrease of $\mathrm{U}_{(\dot{\psi} / \delta \mathrm{H})}$ at the same time, making it possible to reach the desired target values shown in Table 1. Furthermore, the decline of yaw response at high frequencies ( $\mathrm{f}>2 \mathrm{~Hz}$ ) can be compensated, which leads to a very constant yaw behavior over the complete frequency range. The proposed solution shows the fastest response as well as the most
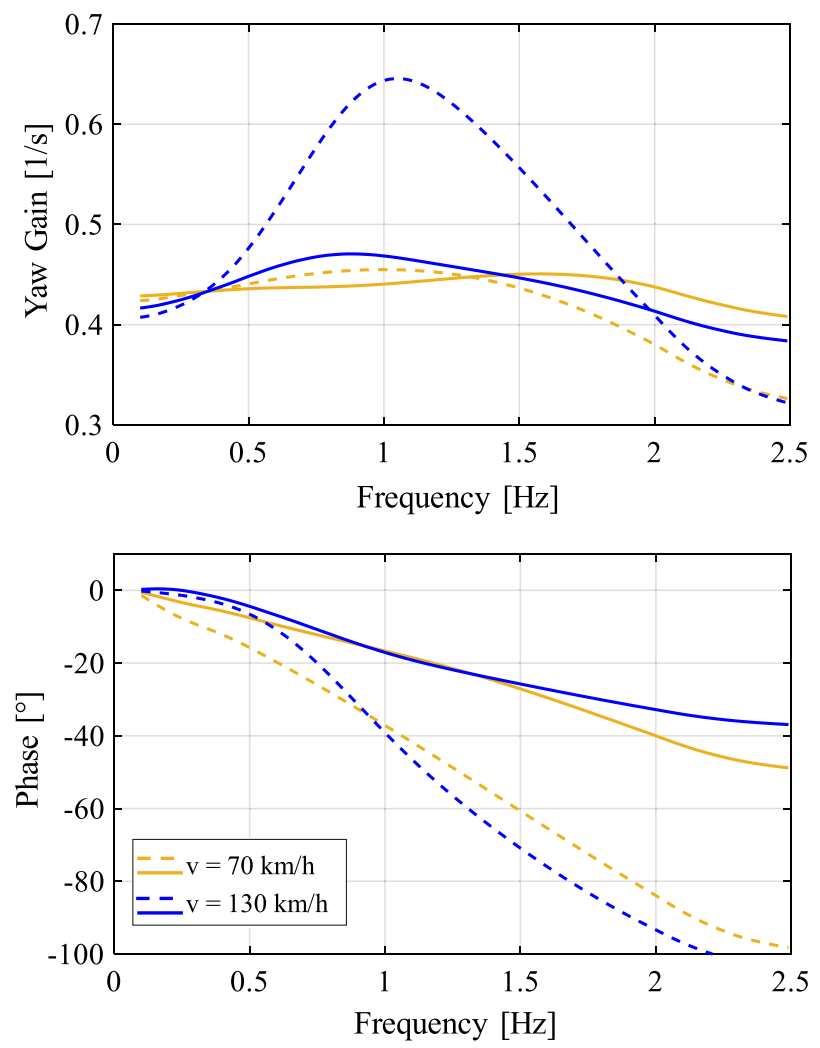

Fig. 13 Frequency response (amplitude and phase) in steering sweep maneuvers at two different velocities, basis is shown as a dashed line, optimized behavior as a solid line constant yaw gain, thus being superior to the basic vehicle behavior as well as conventional lead steering.

The effect of the additional rack position $\mathrm{x}_{\text {Rack,Add }}$ produced by the second order filter with respect to the original, unmodified rack position is shown in Fig. 12. Compared to the original rack position, a lower rack position (approx. 15\%) is applied around the yaw natural frequency, before it is then increased towards higher excitation frequencies. The new transfer behavior advances the phase up to $60^{\circ}$ in a form, that reduces and linearizes the phase delay of the vehicle.

The results shown in Fig. 11 are produced in a steering sweep maneuver at a velocity of $\mathrm{v}=100 \mathrm{~km} / \mathrm{h}$. The second-order transfer behavior of a vehicle, and therefore the dynamic response, is highly dependent on driving velocity [12]. Especially the increased yaw reaction $\mathrm{U}_{(\dot{\psi} / \delta \mathrm{H})}$ at the yaw natural frequency occurs only at higher velocities. To consider this effect, the amount of additional rack position $\mathrm{x}_{\text {Rack,Add }}$ is also based on velocity through the time constants $T_{1}$ and $T_{2}$, Fig. 6 . For both time constants, a linear dependence on velocity is used, but other correlations are possible as well. The results of the proposed concept in steering sweep maneuvers at different velocities, $v=70$ and $130 \mathrm{~km} / \mathrm{h}$, are shown in Fig. 13. At both velocities, the optimized yaw gain is much more constant than the basis. At $\mathrm{v}=70 \mathrm{~km} / \mathrm{h}$ the decrease in yaw gain at high frequencies is reduced, whereas at $v=130 \mathrm{~km} / \mathrm{h}$ the overshoot near the yaw natural frequency is also almost completely compensated. The response speed expressed through the parameter $\mathrm{f}_{\varphi=-45^{\circ}}$, is drastically improved at both driving velocities. At $\mathrm{v}=130 \mathrm{~km} / \mathrm{h}$, the more critical and therefore more important driving velocity, the improvement in amplitude and phase is greatest.

The proposed solution has also been tested with steering angle as well as steering rate signals measured from the CAN-Bus of a test vehicle at a sample time of $\mathrm{t}_{\text {sample }}=10 \mathrm{~ms}$. The results look equally promising as with ideal steering signals used in the simulation. Sampling rate and signal quality do not seem to limit the application in a real vehicle significantly.

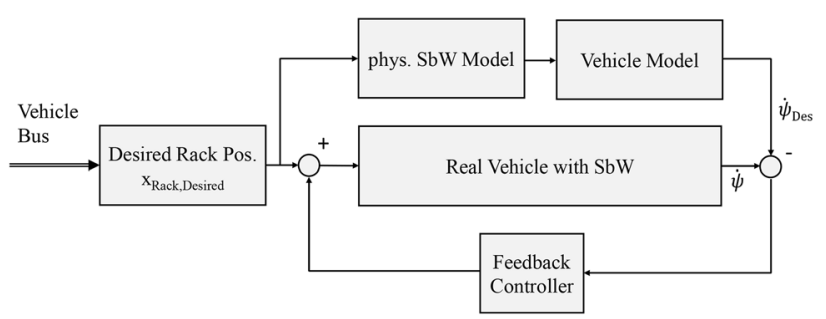

Fig. 14 Combination of the proposed concept for handling improvements with yaw feedback control 


\section{Feedback control}

The proposed concept is used to calculate the desired rack position and is completely open-loop. However, it can easily be combined with any established yaw rate control strategy for stability purposes or to compensate for changes and uncertainties in vehicle parameters. A combination of the proposed concept with yaw rate control is shown in Fig. 14. All proposed functions can be placed inside the first block to generate the desired rack position $\mathrm{x}_{\text {Rack,Desired }}$. The desired rack position is passed to the real vehicle as well as to the simulation model, consisting of a Steer-by-Wire and a vehicle model. An additional input to the real vehicle, based on the difference between the desired and actual yaw rate, is calculated via a feedback controller.

\section{Conclusion}

A concept for a variable steering ratio that takes into account driving velocity, longitudinal and lateral acceleration as well as steering rate has been proposed. Using a velocity-dependent steering ratio known from Active Front Steering systems as a starting point, the potential for tuning the non-linear steering behavior by adding lateral acceleration as an input for the steering ratio concept has been demonstrated. Significant improvements in the dynamic vehicle behavior, especially in yaw damping and response time, have been shown through the combination of lead steering and an optimized second order filter. All improvements in vehicle handling are verified using established objective parameters and validated simulation models. The presented concept for the variable steering ratio can be implemented without restrictions on a real Steer-by-Wire prototype for tests to verify the simulation results.

Funding Open Access funding enabled and organized by Projekt DEAL.

\section{Declarations}

Conflict of interest On behalf of all authors, the corresponding author states that there is no conflict of interest.

Open Access This article is licensed under a Creative Commons Attribution 4.0 International License, which permits use, sharing, adaptation, distribution and reproduction in any medium or format, as long as you give appropriate credit to the original author(s) and the source, provide a link to the Creative Commons licence, and indicate if changes were made. The images or other third party material in this article are included in the article's Creative Commons licence, unless indicated otherwise in a credit line to the material. If material is not included in the article's Creative Commons licence and your intended use is not permitted by statutory regulation or exceeds the permitted use, you will need to obtain permission directly from the copyright holder. To view a copy of this licence, visit http://creativecommons.org/licenses/by/4.0/.

\section{Reference}

1. Koehn, P. and Eckrich, M.:Active steering - the BMW approach towards modern steering technology. SAE Technical Paper (2004)

2. Shimizu, Y., Kawai, T. and Yuzuriha, J.: Improvement in Drivervehicle system performance by varying steering gain with vehicle speed and steering angle: VGS. SAE Technical Paper (1999)

3. Stemmer, M. "Energetische und funktionale Vernetzung von aktiven Lenksystemen. Dissertation (2013)

4. Fuhr, F., Hoffmann, C. and Sagefka, M.: Verfahren zum Beeinflussen eines Eigenlenkverhaltens eines Kraftwagens und ein aktives Lenksystem. Patent DE 102008012006 A1, 2008.

5. Zomotor, A.: Fahrwerktechnik, Fahrverhalten. Vogel Fachbuch, pp. 300-301 (1991)

6. Klier, W., Reimann G. and Reinelt W.: Concept and Functionality of the Active Front Steering System. Convergence International Congress \& Exposition On Transportation Electronics (2004)

7. IPG Automotive: VehicleDynamics - Model-based development and validation of suspension, steering and chassis control systems. https://ipg-automotive.com/fileadmin/user_upload/content/Downl oad/Media/Print/IPG_Automotive_Brochure_Vehicle_Dynamics_ EN.pdf. Accessed 27 Oct 2020

8. Isermann, R.: Fahrdynamik-Regelung. Springer Fachmedien Wiesbaden GmbH (2006)

9. Lunkeit, D.: Ein Beitrag zur Optimierung des Rückmelde- und Rückstellungsverhaltens elektromechanischer Servolenkungen. Dissertation, Universität Duisburg Essen (2014)

10. Harrer M. and Pfeffer, P.: Steering Handbook. Springer International Publishing, pp. 419-420 (2011)

11. Pfeffer, P.: Interaction of vehicle and steering system regarding on-centre handling. Dissertation, University of Bath (2006)

12. Mitschke, M. and Wallentowitz H.: Dynamik der Kraftfahrzeuge. Springer Verlag, pp. 594-595 (2004)

13. Millsap A. and Law E.: Handling Enhancement Due to an Automotive Variable Ratio Electric Power Steering System Using Model Reference Robust Tracking Control. SAE Journal of Passenger Cars (1996)

14. Metz L.: What constitutes good handling?. SAE Technical (2004)

15. Heißing, B., Grunow, D., Rompe, K.: Vergleichende Messungen zum Fahrverhalten von Pkw mit Front-. Heck- und Allradantrieb, Automobil-Industrie (1982)

16. Stock G.: Handlingpotentialbewertung aktiver Fahrwerkregelsysteme. Dissertation, TU Braunschweig (2010)

17. Aurell J., Nordmark S. and Froejd N.: Correlation between Objective Handling Characteristics and Subjective Perception of Handling Quality of Heavy Vehicles. AVEC 2000, 5th international symposium on advanced vehicle control (2000)

18. Jacksch F.: Driver-vehicle interaction with respect to steering controllability. SAE Technical Papers (1979)

Publisher's Note Springer Nature remains neutral with regard to jurisdictional claims in published maps and institutional affiliations. 